\title{
Elevation Bone Grafting and Cancellous Screw Fixation for Type Ii Schatzker Tibial Plateau Fractures
}

\author{
S Vijaya Kumar* \\ Department of orthopaedics, Consultant orthopaedic surgeon, India \\ *Corresponding author: S Vijay Kumar, Department of orthopaedics, Consultant orthopaedic surgeon, India
}

\begin{abstract}
Introduction: Fracture of proximal tibia are especially challenging to surgeons because of their number, variety and complexity. The treatment of tibial plateau fractures is evolving. In this article we are reporting the results of type II Schatzker tibial fracture treated by elevation, bone grafting and cancellous screw fixation.

Aim of Study: To assess the functional outcome after elevation, bone grafting and cancellous screw fixation for type II Schatzker tibial plateau fractures.

Materials and Methods: 12 cases out of 18 cases of type II Schatzker tibial plateau fractures were treated with this method. The articular surface was elevated using cortical window and modified Steinman pin. Packing of medullary cavity with bone graft and cancellous screw fixation was done in all cases. Post operative all cases were immobilized in plaster slab for 4 weeks. Partial weight bearing started at 6 weeks and full weight bearing on fracture union.

Results: All cases were followed up for period of one and half to two and half years. The functional results were assessed by Lysholm knee scale. $83.3 \%$ had good results, the post operative complication noted were superficial infection in 1 case and screw tip irritation in 2 cases. Knee movements were restricted in 2 cases.

Discussion: Most of tibial plateau fractures are treated by surgical methods. The percutaneous and indirect methods of reduction of articular surface are used in type II Schatzker fracture. The C arm is used to assess the reduction. Review of literature shows most of the studies are not specific towards a particular type of fractures. The treatment of tibial plateau fractures is evolving and operative treatment of these fractures require detailed and uniform reporting.

Conclusion: Indirect reduction bone grafting and cancellous screw fixation for type II Schatzher tibial plateau fractures gives good functional results.
\end{abstract}

\section{Introduction}

Fractures of proximal tibia are especially challenging to surgeons because of their number, variety and complexity. The treatment of tibial plateau fractures is evolving. Many articles, written over past years have addressed the problem of classification and results of various treatments available for these fractures. While reviewing these studies it is apparent that results are reported collectively without regard to the fracture type. In this article we are reporting the results of type II tibial plateau fracture treated by elevation of articular surface, bone grafting and cancellous screw fixation [1].

\section{Aim of Study}

To assess the functional outcome after elevation, bone grafting and cancellous screw fixation for type II Schatzher tibial plateau fractures.

\section{Materials and Methods}

The study was conducted in gokulam ortho hospital from Jan. 2016-Feb. 2017. 72 cases had presented to us with tibial condyle fractures. Of these 18 patients had type II Schatzher fracture [2]. Of the 18 cases only 12 were included in study. The inclusion criteria 
were Type II Schatzker fracture, articular surface depression of more than $10 \mathrm{~mm}$. These 12 patients were taken up for surgery immediately. Local skin condition was good and soft tissue oedema was minimal [3]. The limb was positioned in such a way that both $\mathrm{AP}$ and lateral view could be taken easily using image intensifier. A cortical window was made 7 to $8 \mathrm{~cm}$ distal to articular surface on medial side. A Steinmann specially modified (bent at the tip) for elevation was introduced through cortical window and depressed articular fragments were elevated. Elevation was checked under $\mathrm{C}$ arm control. Bone grafts were harvested from iliac crest the medullary cavity was packed. The fracture was then fixed with 6.5 mm cancellous screws. Two sub chondral screws were used. The wounds were closed and Plaster of Paris slab was applied with knee in flexion. Patients were mobilized non weight bearing initially. POP slab was removed at 4 weeks and knee was mobilized with CPM machine. Partial weight bearing was started at 6-8 weeks and full weight bearing was allowed from 12 - 16 weeks depending on fracture healing. The Lysholm knee score was used for assessing the functional outcome after complete healing of fracture [4].

\section{Results}

The total number of cases included in the study are 12 of these 8 were males and 4 were females. The age group ranged from 21 to 65 with a mean age of 43 years. The mode of injury was RTA in 7 cases, fall from height in 1 case and other mode of injury in 4 cases. . Elevation of articular surface bone grafting and cancellous screw fixation was done in all cases. The mean average follow up was one and half year with range of one year to two and half years. At one year follow up the cases were assessed using Lysholm knee scoring scales. Pain, Swelling, Limp Squatting and support for walking were assessed. One case had pain on walking for long distance. One case had persistent knee swelling. Two cases were not able to squat as they were not able to flex the knee. None of the cases needed support for walking. The post operative complication noticed were superficial infection in one case, screw tip irritation in two cases. In all cases fracture had united and none of them had loss of reduction of articular surface. The average union time was 12 to 14 weeks. According to Lysholm knee score. The results were good in $83.3 \%$ of cases and poor in $16.6 \%$ of cases.

\section{Discussion}

Tibial plateau fractures are difficult to treat considering the local skin condition and fear of compartment syndrome. We have done extensive study of literature and found that most of studies have reported their finding in tibial condyle fractures in general. There are few studies which deal with type of fracture and specific management. We decided to find out results of surgical management of type II tibial plateau fractures. The common management of type II fractures was plaster application irrespective of amount of articular surface depression. This led to poor functional outcome and salvage procedures were required. Most surgeons preferred to elevate significantly depressed articular surfaces in an attempt to avoid deformity or instability. The goal of operative treatment is restore the depressed articular surface to its normal level and maintain it until fracture healing occurs [5]. The traditional operative method consists of elevating the depressed articular fragment with an impacter through a window made in the medial tibial flare. Elevation of articular surface is observed directly through an arthrotomy. Arthrotomy as we all know has its own complications. A newer method using arthroscope or fluoroscope was used to observe the reduction. Lokenhoffer P5 compared fluoroscopy and arthroscopy to control reduction. He concluded that percutaneous treatment of fractures of tibial plateau can be performed using arthroscope as well as image intensification to control or asses reduction. Once reduction of articular surface was achieved there was ae large cavity beneath the elevated articular surface. This space was filled by harvesting bone grafts from iliac crest and filling the cavity. This filling with bone grafts gave minimal support to the elevated articular surface. So the elevated articular surface had to maintained at the elevated level. Cancellous screws fixation was done to maintain the articular surface. Boisrenoult P2 had studied efficacy of plate and screw fixation versus double screw fixation for type II Schatzker fracture of lateral tibial plateau. He had concluded that bio mechanical stability of double screw fixation is good for tibial plateau fractures. We in our analysis of type II Schatzker fractures, treated by elevation bone grafting and cancellous screw fixation have found that $83.3 \%$ had good results. Comparing of our results with these studies found that the functional results we obtained were similar to them. For fractures with depression of more than $10 \mathrm{~mm}$ indirect reduction achieves of articular surface. Packing with bone grafts and fixation with two cancellous screws provide adequate support for elevated articular surface. Image intensifier or $\mathrm{C}$-arm machine can be used to assess articular congruence. . Arthrosopy needs training on part of the surgeon. In a country like india the cost of arthroscopy also has to be considered. Careful evaluation of fracture personality and surrounding soft issue, timing of surgery as well as handling of soft tissue can optimize treatment results in tibial plateau fractures [6].

\section{Conclusion}

Elevation, bone grafting and cancellous screw fixation for type II Schatzker tibial plateau fractures gives good functional results. We had found good results using this technique in our study.

\section{References}

1. Gur B, Akman S, Aksoy B, Tezer M, Ozturk I, Kuzgun U, et al (2003) The effect of screw type on fixation of depressed fragments in tibial plateau fractures. Acta Orthop Traumatol Turc 37(20): 113-119.

2. Boisrenoult P, Bricteux S, Beaufils P, Hardy P (2000) Tibial plateau fractures. A review of operative treatment using AO technique Rev Chir Orthop Reparatrice Appar Mot. 2000 Nov; 86(7): 707-11. 
3. Honkonen SE (1994) Indirect reduction and percutaneous screw fixation of displaced tibial plateau fractures. Clin Orthop (302): 199-205

4. Koval KJ, Sanders R, Borrelli J, Helfet D, DiPasquale T, et al. Screws versus screw - plate fixation of type 2 Schatzker fractures of the lateral tibial plateau. Cadaver biomechanical study. Arthroscopy French Society) Hospital for Joint Diseases, Orthopaedic Institute, New York, USA.

5. Lobenhoffer p, Schule M, Gerich T, Lattermann C, Tscherne H, et al. (1999) Closed reduction / percutaneous fixation of tibial plateau fractures: arthroscopic versus fluoroscopic control of reduction. Department of Trauma Surgery, Hannover Medical School, Germany J orthop Trauma 13(6): 426-431.

6. Touliatos AS, Xenakis T, Soucacos PK, Soucacos PN (1997) Indications for surgical treatment of tibial condyle fractures Surgical treatment of tibial plateau fractures. Acta Orthop Scand Suppl 275: 92-96.

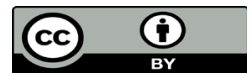

This work is licensed under Creative Commons Attribution 4.0 License

To Submit Your Article Click Here:

Submit Article

DOI: $10.32474 /$ OSMOAJ.2020.04.000180

$\begin{gathered}\text { Orthopedics and Sports Medicine } \\ \text { Open Access Journal }\end{gathered}$
Assets of Publishing with us
- Global archiving of articles
- Immediate, unrestricted online access
- Rigorous Peer Review Process
- Authors Retain Copyrights
Orthopedics And Sports Medicine:
Open Access Journal

